\title{
Keselamatan Kerja di Area Pelabuhan Perikanan Nusantara Palabuhanratu, Sukabumi, Jawa Barat
}

\author{
Occupational Safety in The Palabuhanratu Fishing Port Area, \\ Sukabumi, West Java Province \\ Ayu Asriani ${ }^{1)}$, Fis Purwangka ${ }^{1)}$, Mohammad Imron ${ }^{1)}$ \\ Departemen Pemanfaatan Sumberdaya Perikanan, FPIK Institut Pertanian Bogor \\ Email korespondensi: fis@psp-ipb.org
}

\begin{abstract}
Abstrak
Pelabuhan Perikanan Nusantara Palabuhanratu dibagi menjadi dua wilayah yaitu wilayah kerja dan wilayah pengoperasian. Salah satu faktor yang menunjang keselamatan kerja adalah dengan adanya fasilitas di kedua wilayah tersebut. Pihak pelabuhan sudah berupaya meningkatkan keselamatan masyarakat dan nelayan. Tujuan penelitian ini mengidentifikasi area kerja beserta fasilitas pelabuhan yang menunjang keselamatan kerja dan mengidentifikasi pengelolaan keselamatan kerja di area PPN Palabuhanratu Sukabumi Jawa Barat. Data yang dikumpulkan yaitu data primer dan data sekunder. Data primer ini diperoleh dengan cara wawancara dan kuesioner, sedangkan data sekunder diperoleh dengan cara penelusuran dokumen (peraturan) mengenai keselamatan kerja di laut pada instansi terkait. Pengambilan data dilakukan dengan metode purposive sampling terhadap beberapa pihak yang berkepentingan dengan keselamatan kerja nelayan seputar keselamatan kerja. Fasilitas yang ada di pelabuhan untuk menunjang keselamatan kerja sudah memenuhi sebesar $69 \%$ standar yang berlaku sesuai dengan Peraturan Pemerintah nomor KEP.16/MEN/2006 tentang Pelabuhan Perikanan, peraturan yang sudah ada untuk menyesuaikan SOP yang berlaku mengenai keselamatan kerja di PPN Palabuhanratu, Sukabumi, Jawa Barat. Pihak pengelola PPN Palabuhanratu telah mengacu Peraturan Pemerintah nomor 20/PERMEN-KP/2009 tentang Organisasi dan Tata Kerja unit Pelaksana Teknis Pelabuhan Perikanan. Struktur organisasi PPN Palabuhanratu Sukabumi Jawa Barat memiliki nilai persentase sebesar 70,1\% dengan kategori sedang dalam upaya peningkatan fasilitas pelabuhan.
\end{abstract}

Kata kunci: keselamatan kerja, nelayan, Palabuhanratu

\begin{abstract}
Palabuhanratu fishing port is divided two regions, such as the working area and the operation area. One of the supporting factors of safety is facilities in those two regions. Port management has been working to improve public and fisherman safety. The objectives of the research were to identify or work region and port facility to support safety act and to identify safety act management in Palabuhanratu fishing port Sukabumi West Java. The data collected were primary data and secondary data. The primary data was obtained through interviews and questionnaires; while secondary data was obtained by the document searches concerning safety at sea related institutions. Data were collected by purposive sampling method against several parties concerned with the safety. The existing facilities at the port that was functioning on support for safety work has been already into $69 \%$ of the applicable standards base on government regulation KEP.16/MEN/2006 about fishing port, the existing rules to adjust the operational standards and regulations on occupational safety in PPN Palabuhanratu Sukabumi, West Java. The port management of the PPN Palabuhanratu was following to government regulation No20/PERMEN-KP/2009 about the organization and working procedures of the technical implementation unit of fishing port. PPN the organization structure of Palabuhanratu Sukabumi, West Java has a presentation value of $70.1 \%$ with a medium category in order to increase fishing port facility.
\end{abstract}

Keywords: safety act, fisherman, Palabuhanratu 
Ayu Asriani : Keselamatan Kerja di Area Pelabuhan Perikanan Nusantara Palabuhanratu, Sukabumi, Jawa Barat

\section{Pendahuluan}

Pelabuhan Perikanan Nusantara Palabuhanratu berada di Sukabumi Provinsi Jawa Barat Indonesia dengan posisi koordinat $07^{\circ} \mathrm{s} / \mathrm{d} 07^{\circ}$ 12' Lintang Selatan dan $106^{\circ} 21^{\prime} \mathrm{s} / \mathrm{d} 106^{\circ} 31^{\prime}$ Bujur Timur. Panjang pantai Kabupaten Sukabumi adalah $117 \mathrm{~km}$. Terjadinya kecelakaan pada proses Keselamatan kerja bergantung pada kesadaran akan pentingnya proses kerja beserta tahapannya yang menunjang keselamatan kerja. Dengan semakin banyaknya penggunaan alat-alat kerja yang canggih, walaupun telah dilengkapi dengan sistem keamanan, resiko kecelakaan tetap semakin besar. Salah satu kegiatan yang dilakukan di area pelabuhan adalah aktivitas bongkar muat dari kapal peangkap ikan, aktivitas bongkar muat ini memiliki potensi bahaya dengan kategori tidak bahaya sebanyak $(6 \%)$, ringan $(54 \%)$, menengah $(38 \%)$, dan berat (2\%) (Lestari et. al., 2017) Kebutuhan rasa aman akan muncul setelah kebutuhan tingkat pertama (fisik dan biologis) terpenuhi, sehingga mulai sekarang keselamatan merupakan hal yang harus diusahakan pemenuhannya. Kecelakaan dianggap akibat dari faktor organisasi dan manajemen yang salah. Sejalan dengan teori-teori terbaru, maka peran manajemen sangat berarti dalam pencegahan kecelakaan (Abraham 1996).

Kasus kecelakaan yang terjadi PPN Palabuhanratu pada tahun 2015 adalah terbakarnya kapal yang berada di area penempatan kapal mati. Kecelakaan tersebut disebabkan oleh lemahnya pengawasan pihak yang terlibat karena tidak ada pemeriksaan yang berada di penempatan kapal mati sehingga menyebabkan kebakaran. Kasus kebakaran ini terjadi karena adanya salah satu masyarakat yang mengalami gangguan jiwa menyalakan api di dekat penempatan kapal mati. Api yang semula kecil lama-kelamaan menjadi besar dan mulai menjalar ke bagian kapal yang telah lama rusak. Struktur bagian kapal yang telah lama rusak menjadikan kayu menjadi rapuh dan mudah terbakar oleh api. Masyarakat sekitar baru menyadari setelah api membesar kemudian masyarakat dengan cepat memadamkan api yang membakar kapal.
Dalam tulisan ini, peran manajemen Keselamatan dan Kesehatan Kerja (K3) dibahas dari fungsi manajemen, sumber daya yang digunakan, dan aspek lain yang relevan (Bambang 2006). Berdasarkan observasi ditemukan gambaran umum K3 meliputi: pertama, bahaya $\mathrm{K} 3$ yang ada di lingkungan kerja seperti bahaya K3 fisik, bahaya K3 mekanik, bahaya K3 biologi, K3 kimia, dan bahaya K3 psikososial. Kedua, kurang waspada terhadap faktor resiko terhadap terjadi penyakit akibat kerja meliputi dekompresi, barotrauma, keracunan dan sinus. Ketiga, keterbatasan peralatan yang dipergunakan. Keempat, beban fisik yang tinggi dan waktu kerja yang lama. Kelima, pengetahuan nelayan kompresor mengenai safety dive yang rendah (Robiana 2012). Masalah lainya adalah terbatasnya modal dan teknologi penangkapan ikan, rendahnya kualitas SDM nelayan, lemahnya pengawasan, dan data statistik perikanan tangkap yang kurang akurat, sehingga kenyataannya dibutuhkan persiapan dan pembenahan yang menyeluruh sebelum tahap implementasi program (Anthony 2013). Penelitian ini bertujuan untuk mengidentifikasi area kerja dan fasilitas pelabuhan yang menunjang keselamatan kerja, dan mengidentifikasi pengelolaan keselamatan kerja di area PPN Palabuhanratu Sukabumi Jawa Barat.

Hasil penelitian ini diharapkan memberikan data dan informasi mengenai keselamatan kerja kepada hal layak sesuai dengan keadaan di lapangan, serta dapat menjadi acuan sebagai peningkatan standar keselamatan kerja di PPN Palabuhanratu Sukabumi.

\section{Bahan dan Metode}

Penelitian ini dilakukan di Pelabuhan Perikanan Nusantara (PPN) Palabuhanratu, Sukabumi, Jawa Barat (Gambar 1). Penelitian lapangan dilaksanakan pada tanggal 1 Oktober-Desember 2015. Proses pengolahan data dilakukan di Laboratorium Keselamatan Kerja dan Observasi Bawah Air, Departemen PSP, FPIK Institut Pertanian Bogor. 


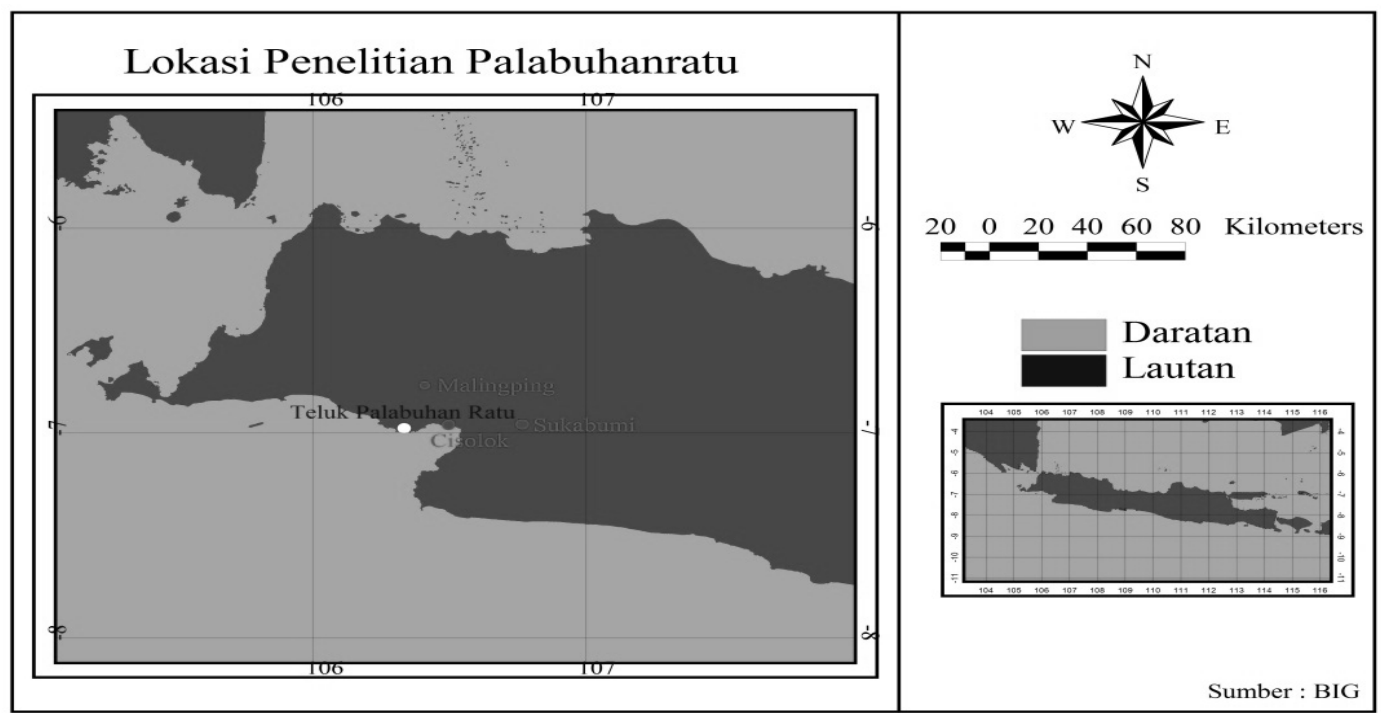

Gambar 1 Peta lokasi penelitian

Figure 1. Map of Research Location

Bahan penelitian adalah kuesioner dan wawancara. Alat-alat yang digunakan dalam penelitian ini adalah alat tulis dan peralatan dokumentasi (kamera) digunakan untuk gambar dan video. Metode penelitian yang digunakan adalah metode penelitian survei dengan studi kasus lapangan, yaitu mempelajari secara intensif latar belakang keadaan terkini pelabuhan berkaitan dengan fasilitas yang telah disediakan pelabuhan untuk menunjang keselamatan kerja di laut.

Penelitian ini bersifat deskriptif (descriptive reasearch) yang dimaksudkan untuk mengeksplorasi dan mengklarifikasi fenomena terkait aspek keselamatan kerja di PPN Palabuhanratu, dengan jalan mendeskripsikan sejumlah variabel yang berkenaan dengan masalah dan unit yang diteliti dengan melakukan penilaian pemenuhan standar kondisi fasilitas dan standar kinerja pada area kerja di pelabuhan. Oleh karena itu, pada suatu penelitian deskriptif, tidak menggunakan dan tidak melakukan pengujian hipotesis (seperti yang dilakukan dalam penelitian eksplanasi); berarti tidak dimaksudkan untuk membangun dan mengembangkan perbendaharaan teori. Dalam pengolahan dan analisis data, lazimnya menggunakan pengolahan statistik yang bersifat deskriptif (statistik deskriptif) (Whitney 1960).

Jenis data yang dikumpulkan dalam penelitian ini meliputi data primer dan data sekunder. Data primer adalah sumber data yang diperoleh secara langsung dari nara sumber melalui wawancara. Data sekunder adalah data yang diperoleh dari instansi terkait. Data sekunder pada umumnya berupa bukti, catatan, atau laporan historis yang telah tersusun dalam arsip, baik yang dipublikasikan dan yang tidak dipublikasikan. (Nevins 1938)

1. Data primer : pengumpulan data primer dilakuakn dengan melakukan pengamatan langsung ke area kerja yang tercakup dalam penelitian ini, serta dilakukan wawancara kepada petugas pelabuhan dengan menggunakan kuesioner.

2. Data sekunder : data sekunder sebagai data pendukung yang diperoleh dengan cara penelusuran dokumen (peraturan) mengenai keselamatan kerja di laut pada instansi, studi literatur, atau referensi lainnya (jurnal, artikel hasil penelitian sebelumnya, dan penelusuran melalui internet).

Analisis deskriptif, Usaha mengumpulkan dan menyusun suatu data, kemudian dilakukan analisis terhadap data tersebut. Analisis isi, Pengkajian secara mendalam mengenai isi atau materi yang terdapat pada dokumen (peraturan) mengenai keselamatan kerja nelayan. Analisis numerik, Cara melakukan perhitungan terhadap data yang diperoleh. Data yang diperoleh dibagi dalam beberapa kriteria dan diberi skor yang selanjutnya disajikan dalam bentuk persentase. Adapun kriteria untuk pemenuhan kompetensi menggunakan skoring yaitu : 
Ayu Asriani : Keselamatan Kerja di Area Pelabuhan Perikanan Nusantara Palabuhanratu, Sukabumi, Jawa Barat

Tabel 1. Kriteria Pemenuhan Standar Fasilitas Pelabuhan

Table 1. Criteria of Fullfillment Port Facilities Standard

\begin{tabular}{ll}
\hline Kriteria pemenuhan standar fasilitas pelabuhan & Skor \\
\hline Baik & 3 \\
Cukup baik & 2 \\
Kurang & 1 \\
\hline
\end{tabular}

Tabel 2. Kriteria Pemenuhan Standar Kinerja Pelabuhan

Table 2. Criteria of Fullfillment of Port Performance Standard

\begin{tabular}{ll}
\hline Kriteria pemenuhan standar kinerja kerja pelabuhan & Skor \\
\hline Baik & 3 \\
Cukup baik & 2 \\
Kurang & 1 \\
\hline
\end{tabular}

Menghitung persentase pemenuhan fasilitas (\%) digunakan rumus sebagai berikut:

$$
\frac{\text { Pemenuhan fasilitas dilapang }}{\text { Pemenuhan fasilitas yang seharusnya }} \times 100 \%
$$

Rata-rata persentase pemenuhan fasilitas (\%) $=\frac{\sum \text { Nilai Persentase area kerja }}{\sum \text { Area Kerja }} \frac{\sum \text { Presentase }}{\sum \text { AreaKerja }}$

\section{Hasil dan Pembahasan}

\section{Area Kerja PPN Palabuhanratu Sukabumi Jawa Barat}

Area kerja di PPN Palabuhanratu Sukabumi Jawa Barat dengan posisi koordinat $07^{\circ}$ Lintang Selatan dan $106,8^{\circ}$ Bujur Barat. Wilayah tersebut terdapat dua bagian wilayah yaitu wilayah kerja dan wilayah pengoperasian. Wilayah kerja daratan pelabuhan perikanan meliputi wilayah daratan yang dipergunakan untuk kegiatan pembangunan dan operasional, fasilitas pokok, fasilitas fungsional, dan fasilitas penunjang. Wilayah pengoperasian daratan PPN Palabuhanratu: meliputi daratan yang berpengaruh langsung terhadap pembangunan pengoperasian PPN Palabuhanratu antara lain akses jalan menuju PPN Palabuhanratu dan kawasan pemukiman nelayan. Wilayah kerja perairan PPN Palabuhanratu: batas wilayah
Menghitung persentase pemenuhan standar kinerja pelabuhan (\%) digunakan rumus sebagai berikut:

$\frac{\text { Pemenuhan kinerja kerja dilapang }}{\text { Pemenuhan kinerja kerja yang seharusnya }} \times 100 \%$

Rata-rata persentase pemenuhan kinerja kerja

$$
(\%)=\frac{\sum \text { Nilai Persentase kondisi lapang }}{\sum \text { Kondisi lapang }}
$$

perairan yang diperlukan untuk kegiatan alur pelayaran, penempatan rambu-rambu navigasi, tempat tambat labuh, tempat bongkar muat, antar kapal perikanan di pelabuhan, tempat olah gerak kapal perikanan, kegiatan kesyahbandaran, perbaikan kapal perikanan.

Wilayah pengoperasian perairan PPN Palabuhanratu: meliputi perairan yang berpengaruh langsung terhadap pengembangan PPN Palabuhanratu antara lain: alur pelayaran kapal perikanan dari dan ke PPN Palabuhanratu, keperluan darurat, kegiatan pemanduan, pembangunan kapal perikanan, uji coba kapal dan penempatan kapal mati. Menetapkan Wilayah Kerja dan Wilayah Pengoperasian PPN Palabuhanratu yang terdiri dari Wilayah Kerja Daratan seluas 43 ha (empat puluh tiga hektar) dan Wilayah Kerja Perairan seluas 72,60 ha (tujuh puluh dua koma enam puluh hektar) serta Wilayah Pengoperasian Daratan seluas 1.381,4 ha 
(seribu tiga ratus delapan puluh satu koma empat hektar) dan Wilayah Pengoperasian Perairan seluas 3.969 ha (tiga ribu sembilan ratus enam puluh sembilan hektar) dengan batas-batas dalam koordinat geografis dan peta wilayah kerja dan wilayah pengoperasian, sesuai dengan keputusan Menteri Kelautan dan Perikanan RI Nomor KEP.10/MEN/2009.

Tabel 3. Pembagian wilayah kerja di PPN Palabuhanratu Sukabumi Jawa Barat.

Table 3. Division of work area in VAT Palabuhanratu Sukabumi West Java

\begin{tabular}{|c|c|c|c|c|}
\hline No. & $\begin{array}{c}\text { Wilayah } \\
\text { Kerja }\end{array}$ & $\begin{array}{l}\text { Kondisi } \\
\text { Lapang }\end{array}$ & $\begin{array}{l}\text { Pemenuhan } \\
\text { Fasilitas }\end{array}$ & $\%$ \\
\hline \multirow[t]{5}{*}{1} & Daratan & & & \\
\hline & $\begin{array}{l}\text { A. Tempat pelelangan } \\
\text { ikan }\end{array}$ & $\begin{array}{l}\text { Kurangnya kesadaran akan kebersihan } \\
\text { (lantai kotor dan licin, limbah ikan yang } \\
\text { berserakan di area pelelangan ikan) }\end{array}$ & Kurang & $33.30 \%$ \\
\hline & B. Coldstorage & $\begin{array}{l}\text { Struktur bangunan yang telah lama } \\
\text { menjadikan coldstorage perlu di perbaiki } \\
\text { agar tidak menyebabkan kecelakaan kerja }\end{array}$ & Sedang & $66.60 \%$ \\
\hline & $\begin{array}{l}\text { C. Tempat } \\
\text { penampungan es }\end{array}$ & $\begin{array}{l}\text { Di wilayah tempat penampungan es tingkat } \\
\text { kebersihannya kurang terlihat dari } \\
\text { lantainya yang licin dan kotor. Penempatan } \\
\text { alat dan bahan yang tidak pada tempatnya } \\
\text { dapat mengganggu aktifitas yang lain. }\end{array}$ & Sedang & $66.60 \%$ \\
\hline & $\begin{array}{l}\text { D. Tempat } \\
\text { penampungan bbm }\end{array}$ & $\begin{array}{l}\text { Bahan bakar minyak yang mudah terbakar } \\
\text { menyebabkan resiko kecelakaan yang } \\
\text { cukup tinggi (ceceran BBM, lantai licin, } \\
\text { kurangnya kesadaran dari pengguna yang } \\
\text { masih banyak merokok di area } \\
\text { penampungan BBM }\end{array}$ & Sedang & $66.60 \%$ \\
\hline \multirow[t]{5}{*}{2} & Perairan & & & \\
\hline & A. Dermaga & $\begin{array}{l}\text { Akses dari dermaga ke kapal rawan } \\
\text { kecelakaan kerja dikarenakan tidak ada } \\
\text { jembatan penghubung }\end{array}$ & Kurang & $33.30 \%$ \\
\hline & B. Kolam & $\begin{array}{l}\text { Kolam di area PPN Palabuhanratu sangat } \\
\text { kotor disebabkan oleh kurangnya } \\
\text { kesadaran dari nelayan akan pentingnya } \\
\text { kebersihan. Masih banyak orang yang } \\
\text { membuang sampah ke kolam. }\end{array}$ & Kurang & $33.30 \%$ \\
\hline & C. Groin & $\begin{array}{l}\text { Groin di PPN Palabuhanratu berfungsi } \\
\text { dengan baik sebagai bangunan penahan } \\
\text { ombak }\end{array}$ & Baik & $100 \%$ \\
\hline & D. Break water & $\begin{array}{l}\text { Breakwater di PPN Palabuhanratu } \\
\text { berfungsi dengan baik karena dapat } \\
\text { menangkal ombak dikala ombak pasang }\end{array}$ & Baik & $100 \%$ \\
\hline
\end{tabular}

Tabel 3 menunjukkan bahwa fasilitas wilayah kerja yang berada di PPN Palabuhanratu Sukabumi Jawa Barat mendapatkan persentase nilai rata-rata sebesar $62.5 \%$ dan mendapatkan nilai cukup dari kriteria nilai yang sudah ditentukan untuk pemenuhan kondisi fasilitas wilayah kerja.

Tabel 4 Pembagian wilayah pengoperasian di PPN Palabuhanratu Sukabumi Jawa Barat.

Table 4. Division of operation area in VAT Palabuhanratu Sukabumi West Java.

\begin{tabular}{cccc}
\hline No & $\begin{array}{l}\text { Wilayah } \\
\text { Pengoperasian }\end{array}$ & Kondisi Lapang & $\begin{array}{c}\text { Pemenuhan } \\
\text { Fasilitas }\end{array}$ \\
\hline 1 & Daratan & & $\%$
\end{tabular}


Ayu Asriani : Keselamatan Kerja di Area Pelabuhan Perikanan Nusantara Palabuhanratu, Sukabumi, Jawa Barat

\begin{tabular}{|c|c|c|c|c|c|}
\hline No & & $\begin{array}{c}\text { Wilayah } \\
\text { Pengoperasian }\end{array}$ & Kondisi Lapang & $\begin{array}{c}\text { Pemenuhan } \\
\text { Fasilitas }\end{array}$ & $\%$ \\
\hline & A. & Akses jalan & $\begin{array}{l}\text { Akses jalan yang berada di area PPN } \\
\text { Palabuhanratu masih bisa digunakan } \\
\text { dengan baik karena hanya sedikit bagian } \\
\text { yang rusak }\end{array}$ & Sedang & $66.60 \%$ \\
\hline & B. & $\begin{array}{l}\text { Pemukiman } \\
\text { Nelayan }\end{array}$ & $\begin{array}{l}\text { Pemukiman nelayan cukup bersih } \\
\text { dikarenakan masyarakat membuang } \\
\text { sampah pada TPS setempat dan } \\
\text { memungkinkan masyarakat hidup sehat } \\
\text { karena lingkungan yang sudah cukup } \\
\text { bersih }\end{array}$ & Sedang & $66.60 \%$ \\
\hline & C. & Pasar Ikan & $\begin{array}{l}\text { Pasar ikan yang berada di PPN } \\
\text { Palabuhanratu berbeda dengan tempat } \\
\text { pelelangan ikan, pasar ikan sudah cukup } \\
\text { bersih namum ada sebagian lantai yang } \\
\text { licin karena banyaknya air yang } \\
\text { berceceran dilantai }\end{array}$ & Sedang & $66.60 \%$ \\
\hline \multirow[t]{4}{*}{2} & & airan & & & \\
\hline & & $\begin{array}{l}\text { Alur pelayaran } \\
\text { dari dan ke } \\
\text { pelabuhan } \\
\text { perikanan }\end{array}$ & $\begin{array}{l}\text { Alur pelayaran perlu ditingkatkan karena } \\
\text { jalan atau akses yang ada kurang } \\
\text { memadai (contoh kasus: tidak ada tangga } \\
\text { dari kapal satu ke kapal lainnya) }\end{array}$ & Kurang & $33.30 \%$ \\
\hline & B. & $\begin{array}{l}\text { Keperluan } \\
\text { keadaan darurat }\end{array}$ & $\begin{array}{l}\text { Perlu ditingkatkan supaya pelayanan } \\
\text { terhadarap nelayan dapat ditangai dengan } \\
\text { cepat }\end{array}$ & Sedang & $66.60 \%$ \\
\hline & C. & $\begin{array}{l}\text { Penempatan } \\
\text { kapal mati }\end{array}$ & $\begin{array}{l}\text { Penempatan kapal mati perlu diperbaiki } \\
\text { dikarenakan penempatan yang kurang } \\
\text { memadai dan rentan terhadapan } \\
\text { kecelakaan (contoh kasus : kebakaran) }\end{array}$ & Kurang & $33.30 \%$ \\
\hline
\end{tabular}

Tabel 4 menunjukkan bahwa fasilitas wilayah kerja yang berada di PPN Palabuhanratu Sukabumi Jawa Barat mendapatkan persentase nilai rata-rata sebesar $66.7 \%$ dan mendapatkan nilai cukup dari kriteria nilai yang sudah ditentukan untuk pemenuhan kondisi fasilitas wilayah pengoperasian. Wilayah kerja dan wilayah pengoperasian mendapatkan nilai rata-rata persentase sebesar $69 \%$ dan mendapatkan nilai cukup dari kriteria nilai yang telah ditentukan untuk pemenuhan kondisi fasilitas keseluruhan, dengan masing-masing kategori yang masih memiliki kekurangan dan perlunya perbaikan. Dari 14 kategori di wilayah kerja dan wilayah pengoperasian diperoleh persentase sebesar $69 \%$ dengan nilai cukup baik.

Berdasarkan Keputusan Menteri Kelautan dan Perikanan RI Nomor KEP.10/MEN/2009 tentang Wilayah Kerja dan Wilayah Pengoperasian PPN Palabuhanratu. Wilayah kerja adalah tempat yang terdiri atas bagian daratan dan perairan yang dipergunakan secara langsung untuk kegiatan kepelabuhanan perikanan, wilayah kerja daratan $0,430 \mathrm{Km}^{2}$ (43 Ha) dan wilayah kerja perairan $0,726 \mathrm{Km}^{2}$
$(72,60 \mathrm{Ha})$. Wilayah kerja memiliki kondisi lapang yang cukup baik, memperoleh persentase sebesar $70.8 \%$.

Pembedaan wilayah kerja daratan dan perairan yang ditandai oleh sebaran yang berwarna hijau dan biru, warna hijau berarti wilayah kerja daratan seluas 43 ha dan warna biru berarti wilayah kerja perairan seluas 72,60 ha. Wilayah operasional memiliki kondisi lapang yang cukup baik dan memperoleh persentase sebesar $62.5 \%$ dengan kategori yang sudah ditentukan.

Berdasarkan Keputusan Menteri Kelautan dan Perikanan RI Nomor KEP.10/MEN/2009 wilayah pengoperasian Pelabuhan Perikanan Nusantara Palabuhanratu sebagaimana dimaksud dalam diktum PERTAMA ditetapkan untuk pengembangan Pelabuhan Perikanan yang berupa alur pelayaran kapal perikanan dari dan ke Pelabuhan Perikanan, keperluan keadaan darurat, kegiatan pemanduan, pembangunan kapal perikanan, uji coba kapal, penempatan kapal mati, akses jalan menuju Pelabuhan Perikanan dan kawasan pemukiman nelayan. Wilayah pengoperasian daratan dan wilayah perairan yang berpengaruh langsung terhadap pengembangan 
operasional PP meliputi daratan yang berpengaruh langsung terhadap pengembangan pengoperasian $\mathrm{PP}$, antara lain akses jalan menuju PP dan kawasan pemukiman nelayan. Dan wilayah pengoperasian perairan meliputi perairan yang berpengaruh langsung terhadap pengembangan $\mathrm{PP}$, antara lain alur pelayaran kapal perikanan dari dan ke PP, keperluan darurat, kegiatan pemanduan, pembangunan kapal perikanan, uji coba kapal, dan penempatan kapal mati.

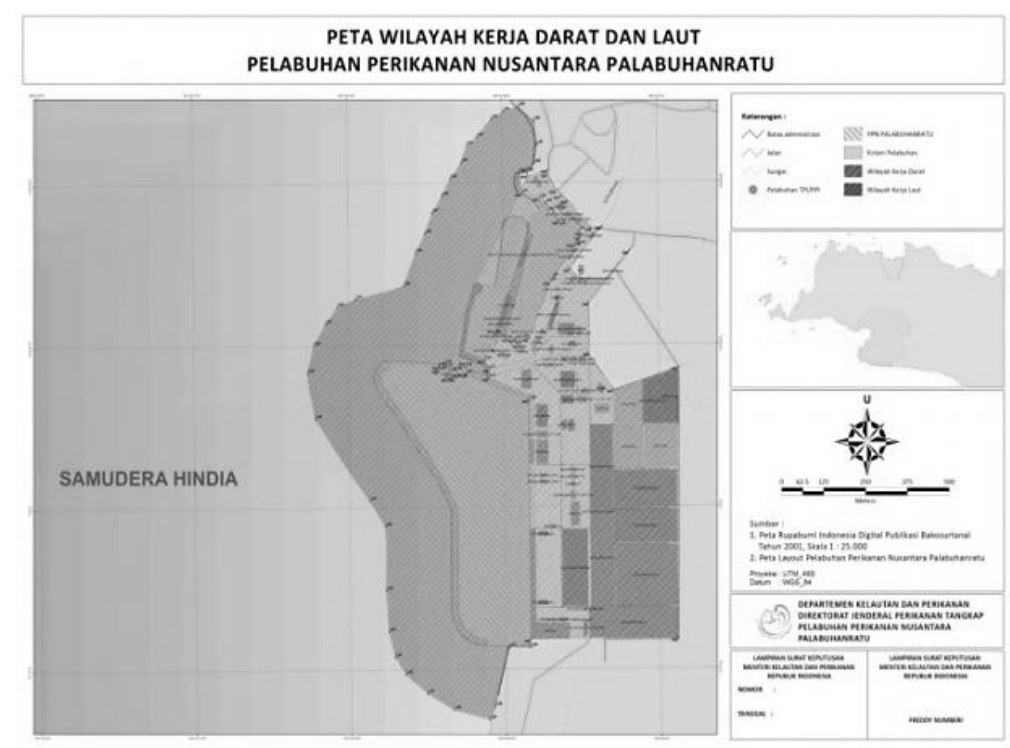

Gambar 2. Peta Wilayah kerja daratan dan perairan PPN Palabuhanratu Sukabumi Jawa Barat. Figure 2. Peta Work area of land and water of PPN Palabuhanratu Sukabumi West Java.

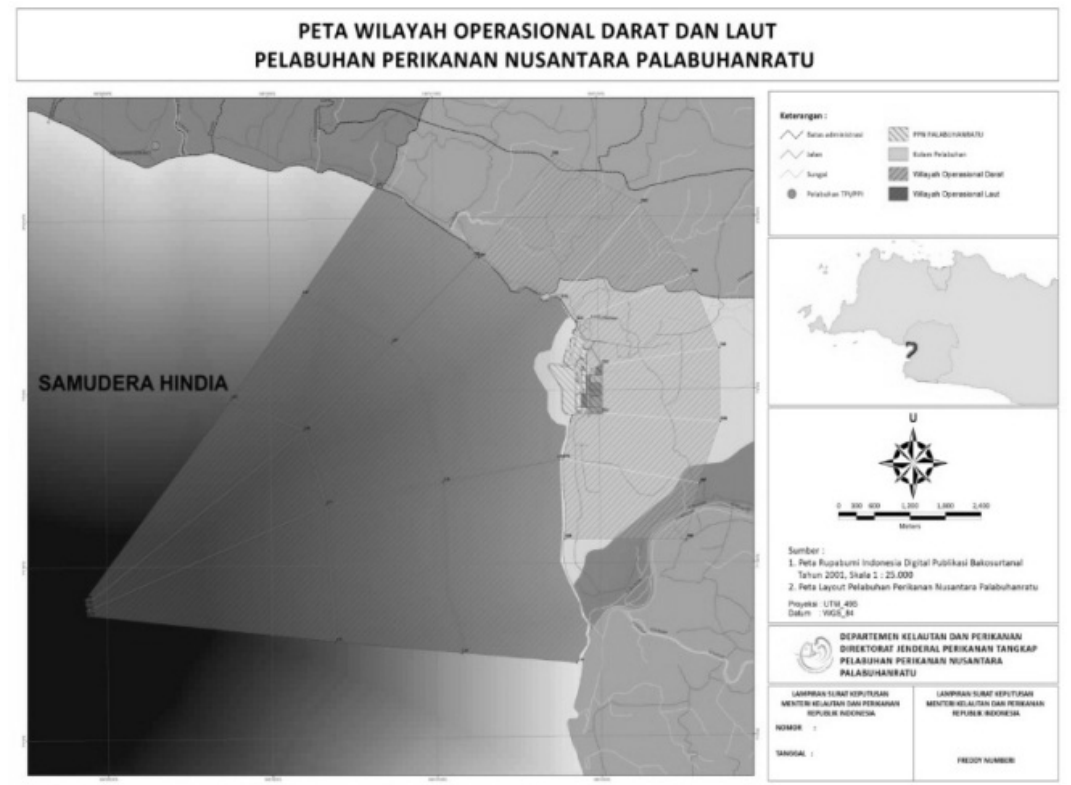

Gambar 3. Peta Wilayah operasional daratan dan perairan PPN Palabuhanratu Sukabumi Jawa Barat. Figure 3. Map The operational area of the mainland and the waters of VAT Palabuhanratu Sukabumi West Java. 
Ayu Asriani : Keselamatan Kerja di Area Pelabuhan Perikanan Nusantara Palabuhanratu, Sukabumi, Jawa Barat

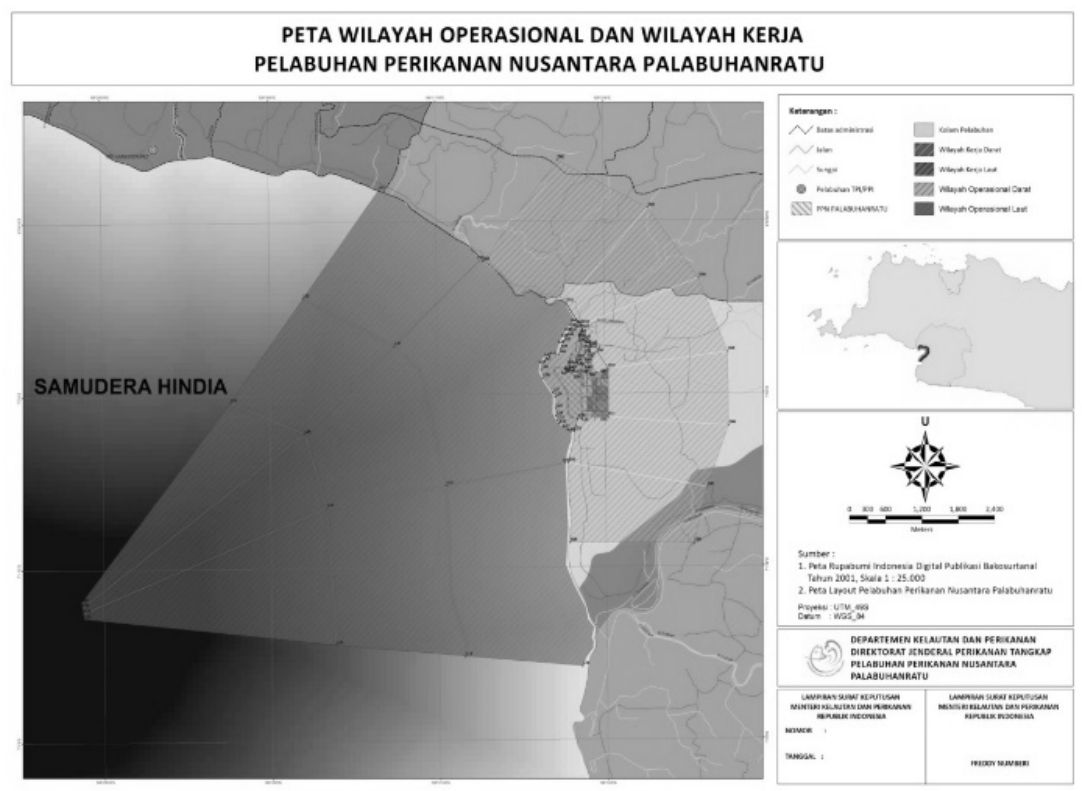

Gambar 4 Peta Wilayah operasional dan wilayah kerja PPN Palabuhanratu Sukabumi Jawa Barat Figure 4. Map Operational area and working area of VAT Palabuhanratu Sukabumi West Java

Berdasarkan Keputusan Menteri Kelautan dan Perikanan RI Nomor KEP.10/MEN/2009 Wilayah pengoperasian Pelabuhan Perikanan Nusantara Palabuhanratu sebagaimana dimaksud dalam diktum PERTAMA ditetapkan untuk pengembangan Pelabuhan Perikanan yang berupa alur pelayaran kapal perikanan dari dan ke Pelabuhan Perikanan, keperluan keadaan darurat, kegiatan pemanduan, pembangunan kapal perikanan, uji coba kapal, penempatan kapal mati, akses jalan menuju Pelabuhan Perikanan dan kawasan pemukiman nelayan. Kondisi wilayah kerja dan wilayah pengoprasian bernilai cukup baik dengan persentase nilai sebesar $68 \%$.

\section{Organisasi Pengelola PPN Palabuhanratu}

Berdasarkan Peraturan Menteri Kelautan dan Perikanan Republik Indonesia nomor
20/PERMEN-KP/2014 tentang organisasi dan tata kerja unit pelaksana teknis pelabuhan perikanan pasal 1, Pelabuhan Perikanan adalah unit pelaksana teknis di bidang pelabuhan perikanan yang berada di bawah dan bertanggung jawab kepada Direktur Jenderal Perikanan Tangkap. Pelabuhan Perikanan sebagaimana dimaksud pada ayat (1) dipimpin oleh seorang Kepala. Pasal 2 Pelabuhan Perikanan mempunyai tugas melaksanakan pengelolaan dan pelayanan pemanfaatan sumber daya ikan, serta keselamatan operasional kapal perikanan. Dalam Struktur Organisasi Pelabuhan Perikanan Nusantara dipelukan 6 bagian terdiri dari: pertama kepala pelabuhan perikanan nusantara, kedua subbagian tata usaha, ketiga seksi operasional pelabuhan, keempat seksi kesyahbandaran, kelima seksi tata kelola dan pelayanan usaha, terakhir adalah jabatan fungsional.

Tabel 5. Struktur organisasi PPN Palabuhanratu Sukabumi Jawa Barat Table 5.The organizational structure of PPN Palabuhanratu Sukabumi West Java

\begin{tabular}{|c|c|c|c|}
\hline \multicolumn{4}{|c|}{ Tingkat Pelaksanaan Teknis } \\
\hline Tugas & Jenis Tugas & $\begin{array}{l}\text { Kondisi } \\
\text { Lapang }\end{array}$ & $\%$ \\
\hline
\end{tabular}

A. Seksi Kesyahbandaran bertugas untuk

$\begin{array}{lll}\text { 1. Pengelola Data Pengelola data bertugas untuk mengelola data } & \text { Sedang } \quad 66.60 \%\end{array}$ yang masuk dari lapang 


\begin{tabular}{|c|c|c|c|c|}
\hline \multicolumn{5}{|c|}{ Tingkat Pelaksanaan Teknis } \\
\hline & Tugas & Jenis Tugas & $\begin{array}{l}\text { Kondisi } \\
\text { Lapang }\end{array}$ & $\%$ \\
\hline 2. & $\begin{array}{l}\text { Petugas Pelayanan } \\
\text { Kebutuhan } \\
\text { Operasional Kapal }\end{array}$ & $\begin{array}{l}\text { Petugas pelayanan bertugas untuk } \\
\text { menyediakan fasilitas yang diperlukan untuk } \\
\text { kebutuhan nelayan }\end{array}$ & Sedang & $66.60 \%$ \\
\hline 3. & $\begin{array}{l}\text { Teknisi Kelaikan } \\
\text { Kapal Penangkap } \\
\text { Ikan }\end{array}$ & $\begin{array}{l}\text { Teknisi kelaikan kapal bertugas untuk } \\
\text { memeriksa kondisi kapal apakah kapal masih } \\
\text { dalam kondisi baik atau perlu adanya } \\
\text { perbaikan }\end{array}$ & Kurang & $33.30 \%$ \\
\hline & Seksi Tata Kelola da & Pelayanan Usaha bertugas sebagai & & \\
\hline & $\begin{array}{l}\text { Petugas pemelihara } \\
\text { dan rehabilitasi } \\
\text { sarana dan } \\
\text { prasarana }\end{array}$ & $\begin{array}{l}\text { Menyediakan fasilitas yang dibutuhkan oleh } \\
\text { pelabuhan supaya tercapai pemenuhan sarana } \\
\text { prasarana. }\end{array}$ & Baik & $100 \%$ \\
\hline & $\begin{array}{l}\text { Petugas } \\
\text { pengawasan dan } \\
\text { pengendalian } \\
\text { pelabuhan } \\
\text { perikanan }\end{array}$ & $\begin{array}{l}\text { Petugas pengawasan bertugas untuk } \\
\text { memeriksa ulang proses kerja di PPN } \\
\text { Palabuhanratu Sukabumi Jawa Barat }\end{array}$ & Sedang & $66.60 \%$ \\
\hline & $\begin{array}{l}\text { Petugas pelayanan } \\
\text { jasa dan fasilitas }\end{array}$ & $\begin{array}{l}\text { Petugas pelayanan jasa dan fasilitas bertugas } \\
\text { untuk memantau kembali pelayanan yang telah } \\
\text { diberikan oleh pihak pelabuhan }\end{array}$ & Sedang & $66.60 \%$ \\
\hline & $\begin{array}{l}\text { Petugas jasa Pas } \\
\text { Masuk }\end{array}$ & $\begin{array}{l}\text { Petugas jasa pas masuk bertugas untuk } \\
\text { memeriksa ulang perlengkapan yang } \\
\text { dibutuhkan untuk melaut }\end{array}$ & Baik & $100 \%$ \\
\hline & Petugas Bengkel & $\begin{array}{l}\text { Petugas bengkel bertugas untuk memperbaiki } \\
\text { alat-alat penglengkapan kapal dan } \\
\text { memperbaiki mesin yang rusak }\end{array}$ & Sedang & $66.60 \%$ \\
\hline
\end{tabular}

Tabel 5 menunjukkan bahwa struktur organisasi PPN Palabuhanratu Sukabumi Jawa Barat memiliki nilai persentase rata-rata sebesar $70.1 \%$ sehingga dapat disimpulkan bahwa kondisi pelaksanaan tugas dilapangan pada struktur organisasi PPN Palabuhanratu bernilai sedang.

\section{Sistem Manajemen Keselamatan dan Kesehatan Kerja}

Berdasarkan Peraturan Pemerintah Republik Indonesia Nomor 50 Tahun 2012 pasal 1 dan 5 tentang Penerapan Sistem Manajemen Keselamatan dan Kesehatan Kerja disajikan pada Lampiran 1. Sistem Manajemen Keselamatan dan Kesehatan Kerja yang selanjutnya disingkat SMK3 adalah bagian dari sistem manajemen perusahaan secara keseluruhan dalam rangka pengendalian risiko yang berkaitan dengan kegiatan kerja guna terciptanya tempat kerja yang aman, efisien dan produktif. Perusahaan adalah setiap bentuk usaha yang berbadan hukum atau tidak, milik orang perseorangan, milik persekutuan, atau milik badan hukum, baik milik swasta maupun milik negara yang mempekerjakan pekerja/buruh dengan membayar upah atau imbalan dalam bentuk lain. Usaha-usaha sosial dan usaha-usaha lain yang mempunyai pengurus dan mempekerjakan orang lain dengan membayar upah atau imbalan dalam bentuk lain. Berdasarkan hal tersebut di atas, PPN Palabuhanratu merupakan organisasi yang ditetapkan oleh Peraturan Menteri Kelautan dan Perikanan Republik Indonesia nomor 20/PERMEN-KP/2014, sebaiknya menjalankan mandat Peraturan Pemerintah Republik Indonesia Nomor 50 Tahun 2012 pasal 1 dan 5.

Berdasarkan Peraturan Menteri Tenaga Kerja Nomor 05 Tahun 1996 pengertian Sistem Manajemen K3 adalah bagian dari sistem manajemen secara keseluruhan meliputi: Struktur organisasi, perencanaan, tanggung jawab, pelaksanaan, prosedur, proses dan sumberdaya yang dibutuhkan bagi pengembangan, penerapan pencapaian, pengkajian dan pemeliharaan kebijakan keselamatan dan kesehatan kerja. Prinsip 
Ayu Asriani : Keselamatan Kerja di Area Pelabuhan Perikanan Nusantara Palabuhanratu, Sukabumi, Jawa Barat

Penerapan Sistem Manajemen Keselamatan dan Kesehatan Kerja sesuai Permenaker No.05 tahun 1996 Sistem Manajemen Keselamatan dan Kesehatan Kerja yang selanjutnya disebut Sistem Manajemen K3 adalah bagian dari sistem manajemen secara keseluruhan yang meliputi struktur organisasi, perencanaan, tanggung jawab, pelaksanaan, penerapan, pencapaian, pengkajian dan pemeliharaan kebijakan keselamatan dan kesehatan kerja dalam rangka pengendalian resiko yang berkaitan dengan kegiatan kerja guna terciptanya tempat kerja yang aman, efesien dan produktif (Pangkey F. et al. 2012). Tempat Kerja adalah setiap ruangan atau lapangan, tertutup atau terbuka, bergerak atau tetap, dimana tenaga kerja bekerja, atau yang sering dimasuki tenaga kerja untuk keperluan suatu usaha dan dimana terdapat sumber atau sumber-sumber bahaya baik di darat, di dalam tanah, di permukaan air, di dalam air, di udara yang berada di dalam wilayah kekuasaan hukum Republik Indonesia. Manajemen keselamatan dan kesehatan kerja (K3) disajikan pada Lampiran 1.

Audit adalah pemeriksaan secara sistematik dan independen, untuk menentukan suatu kegiatan dan hasil-hasil yang berkaitan sesuai dengan peraturan yang direncanakan, dilaksanakan secara efektif dan cocok untuk mencapai kebijakan dan tujuan perusahaan (Peraturan Menteri Tenaga Kerja Nomor 05 tahun 1996 tentang Sistem dan Manajemen Keselamatan dan Kesehatan Kerja). Tujuan dan sasaran Sistem Manajemen K3 adalah menciptakan suatu sistem keselamatan dan kesehatan kerja di tempat kerja dengan melibatkan unsur manajemen, tenaga kerja dan lingkungan kerja yang terintegrasi dalam rangka mencegah dan mengurangi kecelakaan dan penyakit akibat kerja serta terciptanya tempat kerja yang aman, efisien dan produktif. Pengurus harus menunjukkan kepimpinan dan komitmen terhadap keselamatan dan kesehatan kerja dengan menyediakan sumberdaya yang memadai. Pengusaha dan pengurus perusahaan harus menunjukkan komitmen terhadap keselamatan kerja. Perusahaan harus membuat perencanaan yang efektif guna mencapai keberhasilan penerapan dan kegiatan Sistem Manajemen K3 dengan sasaran yang jelas dan dapat diukur. Perencanaan harus memuat tujuan, sasaran dan indikator kinerja yang diterapkan dengan mempertimbangkan identifikasi sumber bahaya, penilaian dan pengendalian risiko sesuai persyaratan perundangan yang berlaku serta hasil pelaksanaan tinjauan awal terhadap keselamatan dan kesehatan kerja. Pelaksanaan tiap prinsip dari 5 prinsip penerapan SMK3 harus berurutan dan mengacu pada prinsip Plan, Do, Check, and Improvement (PDCI), sehingga konsisten dan berkelanjutan yang pada akhirnya kriteria tiap unsur audit SMK3 dapat dipenuhi (Silaban, dkk. 2009).

Dalam mencapai tujuan keselamatan dan kesehatan kerja perusahaan harus menunjuk personal yang mempunyai kualifikasi yang sesuai dengan sistem yang diterapkan. Menurut Pandhu PW. dkk. 2017, kurangnya komunikasi antar seluruh personil adalah sesuatu yang terpenting dan bernilai yang dapat berdampak buruk pada suatu pekerjaan. Perusahaan harus memiliki sistem untuk mengukur, memantau dan mengevaluasi kinerja Sistem Manajemen K3 dan hasilnya harus dianalisis guna menentukan keberhasilan atau untuk melakukan identifikasi tindakan perbaikan. Hal yang paling penting adalah bahwa penerapan K3 ini memberikan dampak atau implikasi terhadap mutu dan produktivitas kerja karyawan (Salafudin M dkk. 2013). Pimpinan yang ditinjau harus melaksanakan tinjauan ulang Sistem Manajemen K3 secara berkala untuk menjamin kesesuaian dan keefektifan yang berkesinambungan dalam pencapaian kebijakan dan tujuan keselamatan dan kesehatan kerja. Ruang lingkup tinjauan ulang Sistem Manajemen K3 harus dapat mengatasi implikasi keselamatan dan kesehatan kerja terhadap seluruh kegiatan, produk barang dan jasa termasuk dampaknya terhadap kinerja perusahaan.

Organisasi dan sistem kerja di PPN Palabuhanratu khususnya, untuk meningkatkan keselamatan dan kesehatan kerja di PPN Palabuhanratu sebaiknya disesuaikan dengan aturan yang berlaku sehingga diharapkan dapat meningkatkan efektifitas pelayanan.

\section{Kesimpulan dan Saran}

\section{Kesimpulan}

1. Fasilitas yang ada di pelabuhan untuk menunjang keselamatan kerja sudah memenuhi sebesar 69\% standar yang berlaku sesuai dengan peraturan pemerintah nomor 20/PERMEN-KP/2014 dan peraturan yang sudah ada untuk menyesuaikan SOP yang berlaku 
mengenai keselamatan kerja di PPN Palabuhanratu, Sukabumi, Jawa Barat.

2. Pihak pelabuhan selaku pengelola PPN Palabuhanratu yang mengacu pada peraturan pemerintah nomor KEP.10/MEN/2009 tentang pembagian wilayah kerja dan wilayah operasional daratan dan perairan dengan dibantu instansi yang lainnya. Struktur organisasi PPN Palabuhanratu Sukabumi Jawa Barat memiliki nilai persentase sebesar $70.1 \%$ dengan kategori sedang. Pihak pelabuhan sedikit demi sedikit sudah berupaya meningkatkan keselamatan masyarakat dan nelayan.

\section{Saran}

Adanya sosialisasi yang diberikan pihak pelabuhan dan pihak polair telah memenuhi standar yang berlaku namun perlu adanya sosialisasi tambahan ke nelayannelayan dan masyarakat yang ada di wilayah PPN Palabuhanratu yang tidak kurang aktif dalam organisasi nelayan supaya keseluruhan nelayan mengetahui dampak dan keadaan cuaca yang ada agar tingkat keselamatan kerja di PPN Palabuhanratu meningkat. Kemudian perlu adanya bantuan modal usaha untuk para nelayan supaya nelayan tidak memiliki hutang pada tengkulak supaya hutang yang dimiliki nelayan tidak turun menurun kepada anak cucunya.

\section{Daftar Pustaka}

[KEPMEN] Keputusan Menteri Perikanan dan Kelautan RI No. 10/Men/2011 tentang: Pembagian Wilayah Kerja dan Wilayah Operasional Daratan dan Perairan. Jakarta (ID): Kementrian Kelautan dan Perikanan Republik Indonesia: Hal lampiran

[KEPMEN] Keputusan Menteri Perikanan dan Kelautan RI No. 39/Men/2011 tentang: Perubahan atas Keputusan Menteri Perikanan dan Kelautan No. 32/Men/2010 Penetapan Kawasan Minapolitan. Jakarta (ID): Kementrian Kelautan dan Perikanan Republik Indonesia: Hal lampiran

Abraham M. 1996. Motivasi dan Kepribadian I. Jakarta (ID): PT PBP.

Anthony N. Robert 2013. Sistem Pengendalian Manajemen Jilid 1. Tanggerang (ID): Karisma Publishing Grup.
Bambang M. 2006. Keselamatan dan Kesehatan Kerja.Semarang (ID): Cahaya Ilmu.

Keputusan Menteri Kelautan dan Perikanan Republik Indonesia Nomor Kep.10/Men/2011 tentang pembagian wilayah kerja dan wilayah operasional daratan dan perairan

Keputusan Menteri Kelautan dan Perikanan Republik Indonesia Nomor Kep.39/Men/2011 Perubahan Atas Keputusan Menteri Perikanan Dan Kelautan Nomor Kep.32/Men/2010 tentang Penetapan Kawasan Minapolitan.

Lestari DA, Fis Purwangka, Budhi H. Iskandar. 2017. Dentifikasi Keselamatan Kerja Kegiatan Bongkar Muat Kapal Purse Seine Di Muncar, Banyuwangi. Journal SAINTEK PERIKANAN: Indonesian Journal of Fisheries Science and Technology. 13 (1): 3137

Menteri Kelautan dan Perikanan RI.2001. Peraturan Menteri Kelautan dan Perikanan Republik Indonesia No.69/PERMEN-KP/2001 tentang kepelabuhan pelabuhan.Jakarta (ID): Kementerian Kelautan dan Perikanan Republik Indonesia. Hal lampiran

Menteri Kelautan dan Perikanan RI.2012. Peraturan Menteri Kelautan dan Perikanan Republik Indonesia No.50/PERMEN-KP/2012 tentang sistem manajemen keselamatan dan kesehatan kerja.Jakarta (ID): Kementerian Kelautan dan Perikanan Republik Indonesia. Hal lampiran

Menteri Kelautan dan Perikanan RI.2014. Peraturan Menteri Kelautan dan Perikanan Republik Indonesia No.20PERMEN-KP/2014 tentang organisasi dan tata kerja unit pelaksaan teknis pelabuhan perikanan.Jakarta (ID): Kementerian Kelautan dan Perikanan Republik Indonesia. Hal lampiran

Menteri Tenaga Kerja RI. 1996. Peraturan Tenaga Kerja Republik Indonesia No. 05/PERMEN/1996 tentang sistem dan manajemen keselamatan dan kesehatan kerja. Jakarta (ID): Kementerian Tenaga Kerja Republik Indonesia. Hal lampiran 
Ayu Asriani : Keselamatan Kerja di Area Pelabuhan Perikanan Nusantara Palabuhanratu, Sukabumi, Jawa Barat

Nevins A. 1938. Gateway to History.New York (USA): Appleton Century Co

Pandhu Prayogo W., Galih Malik Dwi, Bambang Tutuko. 2017. Analisis Penerapan Sistem Manajemen Keselamatan dan Kesehatan Kerja (SMK3) dalam Proyek Pembangunan Pelabuhan di Kabupaten Kendal. TEKNIKA. 12 (2): 29-36.

Pangkey Febyana, Grace Y. Malingkas dan D.O.R. Walangitan.2012. Penerapan Sistem Manajemen Keselamatan Dan Kesehatan Kerja (SMK3) pada Proyek Konstruksi di Indonesia (Studi Kasus: Pembangunan Jembatan Dr. Ir. Soekarno-Manado). Jurnal Ilmiah MEDIA ENGINEERING 2 (2): 100-113.

Peraturan Menteri Kelautan dan Perikanan Republik Indonesia Nomor 20/Permen-KP/2014 tentang organisasi dan tata kerja unit pelaksanaan teknis pelabuhan perikanan.

Peraturan Menteri Tenaga Kerja Nomor PER.05/MEN/1996 tentang Sistem dan Manajemen Keselamatan dan Kesehatan Kerja

Peraturan Pemerintah No.69 Tahun 2001 Pasal 1 ayat 1 , tentang Kepelabuhanan, pelabuhan

Robiana N. 2012. ManfaatPenerapan dan Program Keselamatan dan Kesehatan Kerja. Jakarta (ID): Ikatan Ahli Kesehatan Masyarakat Indonesia.

Salafudin M., Henry Ananta, Subiyanto. 2013. Implementasi Sistem Manajemen Keselamatan dan Kesehatan Kerja di PT PLN (Persero) Area Pengatur Distribusi Jawa Tengah \& D.I.Yogyakarta dalam Upaya Peningkatan Mutu dan Produktivitas Kerja Karyawan. Jurnal Teknik Elektro 5 (1): 26-31.

Silaban G., Soebijanto, Adi Heru Soetomo, Lientje Setyawati Maurits, Suma'mur, P.K. 2009. Kinerja Penerapan Sistem Manajemen Keselamatan dan Kesehatan Kerja Perusahaan Peserta Program Jaminan Kecelakaan Kerja pada PT Jamsostek Cabang Medan. Jurnal Manajemen Pelayanan Kesehatan 12 (3): 130139.
Undang - undang Keselamatan Kerja N0.1. Tahun 1970, pasal 12b dan pasal 12c.

Whitney F.L. 1960. A four year continuation study of a teachers college class. New York (USA): education resque. 